Asian-Australasian Journal of Food Safety and Security ISSN 2523-1073 (Print) 2523-2983 (Online) www.ebupress.com/journal/aajfss

\title{
Article \\ Leaf phenolics and pigments along with their antioxidative potential in some medicinal plants
}

\author{
Rumana Islam, Md. Injamum-Ul-Hoque, Md. Ashrafuzzaman and Md. Nesar Uddin* \\ Department of Crop Botany, Bangladesh Agricultural University, Mymensingh-2202, Bangladesh
}

*Corresponding author: Professor Dr. Md. Nesar Uddin, Department of Crop Botany, Bangladesh Agricultural University, Mymensingh-2202, Bangladesh. E-mail: nesar.uddin@bau.edu.bd

Received: 06 November 2018/Accepted: 27 November 2018/ Published: 29 November 2018

\begin{abstract}
Medicinal plants play significant role in human health. Besides this all of the Unani, Herbal, Kobiraji, and Homeopath medicine are produced from medicinal plant. The aim of the present study was to evaluate the phytochemical constituents as total phenolics content, free radical scavenging capacity, chlorophyll a, chlorophyll $\mathrm{b}$, total chlorophyll $(\mathrm{a}+\mathrm{b})$ and carotenoids. Leaves of seven important non-solanaceous medicinal plants namely Boerhavia diffusa (punarnava), Adhatoda vasica (basok), Paederia foetida (gandhabhaduli), Rauwolfia serpentina (sarpogandha), Catharanthus roseus (pink nayantara), Catharanthus alba (white nayantara) and Andrographis paniculata (kalomegh) were extracted for phenolics, chlorophyll a and $\mathrm{b}$ as well as carotenoids in this experiment. Total phenolics content in seven medicinal plants in this experiment ranged from 142.44 (C. roseus) to 416.25 (A. vasica) $\mathrm{mg}$ GAE/100 g leaf fresh weight. The $\mathrm{IC}_{50}$ value for scavenging 2, 2- diphenyl-1- picrylhydrazyl (DPPH) free radicals ranged from 32.12 (C. roseus) to 38.40 (Boerhavia diffusa) $\mathrm{mg} \mathrm{mL}^{-1}$ leaf extract in seven different medicinal plants. Pigments content such as chlorophyll a, chlorophyll $\mathrm{b}$, chlorophyll $(\mathrm{a}+\mathrm{b})$ and carotenoids were found highest in Adhatoda vasica leaf as 2.347, $0.900,3.283$, and $0.521 \mathrm{mg} \mathrm{g}^{-1}$ fresh weight, respectively, among all the seven species. We may get highly valuable medicine from Adhatoda vasica (basok) leaf for its superior biochemical constituents, which will help our next generation to treat chronic diseases.
\end{abstract}

Keywords: phenolics; free radical; pigments; chronic diseases

\section{Introduction}

The plants used for healing several diseases are called medicinal plant. They have different variety and diversity. Most of them have been used for Ayurvedic, Unani and folk medicine since the prehistoric time. They have been used all over the world for thousands of years as natural medicines possessing therapeutic and other pharmacological effect (Skrovankova et al., 2012). Traditional medicinal plants are often cheaper, locally available and easily consumable, raw or as simple medicinal preparations. Boerhavia diffusa of family Nyctaginaceae is a potential ethno pharmacological herb throughout the world that has been reported to use in treating fever, inflammations, constipation, anemia, cardiac ailments, jaundice, ophthalmia, bronchitis and dyspepsia (Mishra et al., 2014; Nadeem et al., 2012). Justicia adhatoda belonging to family Acanthaceae, commonly known as Basok, is a small, evergreen shrub with a multitude of uses in traditional Ayurveda (Sanjeev and Nayan, 2015). Also, Rauvolfia serpentina, a plant from Apocynaceae, is enriched with a large number of alkaloids, and over 30 alkaloids have been isolated from this plant so far (Rathi et al., 2013). Catharanthus roseus (pink) and Catharanthus alba (white), both are from Apocynaceae that have immense medicinal value in addition of being ornamental. They are used as a traditional folk remedy to cure diabetes and malaria and has been reported to contain anti-cancerous phyto-constituents (Sain and Sharma, 2013). Paederia foetida, from Rubiaceae has long been used as tonic, diuretic, and good for liver and stomach troubles and lumbago. It is regarded as a specific for treating rheumatic affections, in which it is administered both internally 
and externally (Yusuf et al., 2009). Andrographis paniculata is an annual herbaceous plant in the family Acanthaceae which has several potential mechanisms of action relevant in the treatment of acute upper respiratory tract infections including anti-inflammatory (Shen et al., 2002).

The plants are selected on the basis of their traditional use, chemical content and combination of several criteria. The most common strategy is careful observation of the use of natural resources in folk medicine in different cultures; which is usually known as ethnobotany or ethnopharmacology. Keeping these selection criteria in mind, I have selected seven medicinally important plants for my research work. Ceaselessly some of these seven important medicinal plants have been studied separately by the scientists for their phenolics content, DPPH radical scavenging capacity and pigment content. Analyzing these plants for their total soluble phenolics, antioxidative power to scavenge free radical and pigments content would provide a better understanding of relative importance of these medicinal plants in each group as natural antioxidants in the defense against oxidative stress. Keeping this view in mind laboratory studies were done to assess and compare total phenolics content in different medicinal plants; to determine radical scavenging ability of plant extracts as an index of antioxidative power of these plants against oxidative stress; and to quantify carotenoids content in these plant samples.

\section{Materials and Methods}

\subsection{Plant materials and experimental sample collection}

Seven important medicinal plants, namelyBoerhavia diffusa L. (punarnava), Paederia foetida L. (gandhabhaduli), Justicia adhatoda L. (basok), Catharanthus roseus L. (pink nayantara), Catharanthus alba L. (white nayantara), Andrographis paniculata Nees. (kalomegh) and Rauvolfia serpentina L. (sarpogandha) were collected from the medicinal plants repository of Botanical Garden of Bangladesh Agricultural University, Mymensingh. For each plant species studied, three different plants were considered as three replicates. The plants shoots were collected in the Ziploc bag and brought to the laboratory for chemical analyses. Tender leaves of each replicate were chopped to make a composite sample.

\subsection{Phytochemical and biochemical characterization}

\subsubsection{Total phenolics content assay}

Total phenolics compound assayed with the method modified after Albano and Miguel (2011). Exactly $5 \mathrm{~g}$ of working samples for leaf or fruit were taken to a $250 \mathrm{~mL}$ beaker and $100 \mathrm{~mL}$ ice cooled methanol were added to it and then the samples were homogenized for 2 minutes using OV-5 Homogenizer, VELP, Italy. The mixture was kept for 30 minutes in the dark condition and centrifuged for 5 minutes at $1500 \mathrm{rpm}$ and then its supernatant was treated as working sample extract. An aliquot amount of extract was used for determining total phenolics content or DPPH scavenging activity. Gallic acid was used here as standard. Exactly, $330 \mu \mathrm{L}$ different concentrations of gallic acid solutions or suitable amount of plant extracts were taken into a $50 \mathrm{~mL}$ test tube. Then $0.16 \mathrm{~mL}$ of Folin-Ciocalteu reagent and $3 \mathrm{~mL}$ of $\mathrm{Na}_{2} \mathrm{CO}_{3}(10 \%)$ solution was added to $1 \mathrm{~mL}$ of gallic acid solution. The mixture was kept in dark condition for half an hour at room temperature (250C).

Then absorbance was measured at $760 \mathrm{~nm}$. The absorbance value is the reflection of the total phenolic content of the compound. After plotting the absorbance in ordinate against the concentration a linear relationship was obtained which was used as a standard curve for the determination of the total phenolics content of the test samples.

\subsubsection{DPPH radical scavenging assay}

Free radical scavenging activity of the medicinal plant extracts were determined by using a stable 2, 2-diphenyl1-picrylhydrazyl radical (DPPH) (Brand-Williams et al., 1995). DPPH is a free radical of violet colour. The antioxidants in the sample scavenge the free radicals and turn it into yellow colour. The change of colour from violet to yellow is proportional to the radical scavenging activity. Briefly, the assay contained $2.7 \mathrm{~mL}$ of $0.1 \mathrm{mM}$ DPPH in methanol and made up to $3 \mathrm{~mL}$ with $300 \mu \mathrm{L}$ plant extracts (working sample). The contents were mixed well immediately and then incubated for $30 \mathrm{~min}$ at room temperature $\left(25^{\circ} \mathrm{C}\right)$. The degree of reduction of absorbance was recorded at $517 \mathrm{~nm}$ using DR $6000 \mathrm{UV}$ Spectrophotometer. The percentage of scavenging activity was calculated as:

$(\mathrm{Ac}-\mathrm{As}) / \mathrm{Ac} \times 100$

where 'Ac' is the absorbance of control (without extract) and 'As' is the absorbance of sample with plant extract. Percentage of radical scavenging activity was plotted against the corresponding concentration of the extract to obtain IC50 value. IC50 is defined as the amount of antioxidant material required to scavenge 50\% of 
free radical in the assay system. The IC50 values are inversely proportional to the antioxidant activity (Nisha $e t$ al., 2009).

\subsubsection{Pigments determination}

This protocol describes how the contents of chlorophyll-a, b and total carotenoids can be determined in a whole pigment extract of green plant tissue by spectrophotometer (Lichtenthaler, 1987). From the fresh composite leaf or fruit samples, $50 \mathrm{mg}$ were taken in glass bottles and $200 \mu \mathrm{L}$ distilled water were added to it. Then $16 \mathrm{~mL}$ ethanol were added and shaken properly and finally the content was kept in dark condition for $24 \mathrm{~h}$. Absorbance reading was taken in the following day in a spectrophotometer (DR 6000, Hach, USA) at 470, 649, 664 and 750 $\mathrm{nm}$ wave lengths. Afterward, amount of total carotenoids (sum of carotene and xanthophylls) were calculated using the following formulae:

Carotenoids $(\mathbf{C} \mathbf{x}+\mathbf{c})=(4.785$ A470+3.657 A664-12.76 A649) $\times 16.2 / \mathrm{FW}$

Where,

A649 = Absorbance at $649 \mathrm{~nm}$

A664 = Absorbance at $664 \mathrm{~nm}$

A470 = Absorbance at $470 \mathrm{~nm}$

$\mathrm{FW}=$ Fresh weight of plant tissue $(\mathrm{mg})$

\subsubsection{Statistical analysis}

Mean values of each parameter studied for each group of medicinal plants were subjected to one way ANOV Analysis using Minitab 17.3 to determine whether significant differences in the group existed or not. In case of having significant $F$-ratio, means were subjected to Tukey's post-hoc test to observe the significant differences among the mean values.

\section{Results}

\subsection{Total soluble phenolics}

Methanolic extracts of leaves of seven important medicinal plants, namely Boerhavia diffusa L. (punarnava), Paederia foetida L. (gandhabhaduli), Justicia adhatoda L. (basok), Catharanthus roseus L. (pink nayantara), Catharanthus alba L. (white nayantara), Andrographis paniculata Nees. (kalomegh) and Rauvolfia serpentina L. (sarpogandha) were tested to determine total phenolics as gallic acid equivalent (GAE) per $100 \mathrm{~g}$ fresh weight (Figure 1). Phenolics content in leaves of seven different medicinal plants varied significantly and ranged from 142.44 to $416.25 \mathrm{mg} \mathrm{GAE} / 100 \mathrm{~g}$ fresh weight (Figure 1). The highest amount of total soluble phenolics was recorded in Justicia adhatoda leaf (416.25 mg GAE/100 g FW) followed by Boerhavia diffusa (264.25 mg GAE/100 g FW) and Rauvolfia serpentina (245.21 mg GAE/100 g FW). Statistically the lowest amount of phenolics was shared by Paederia foetida (165.81 mg GAE/100 g FW), Catharanthus alba (166.25 mg GAE/100 g FW) and Catharanthus roseus leaves (142.44 mg GAE/100 g FW). Considering the phenolics content of Justicia adhatoda leaves (416.26 mg GAE/100 g FW) as 100\%, the relative phenolics contents in Boerhavia diffusa, Paederia foetida, Catharanthus roseus, Catharanthus alba, Andrographis paniculata and Rauvolfia serpentina were calculated as 63.5, 39.8, 34.2, 39.9, 45.4 and 58.9\%, respectively.

\subsection{DPPH scavenging capacity of seven different medicinal plants}

The $\mathrm{IC}_{50}$ value (the amount of antioxidant material required to scavenge $50 \%$ of free radical in the assay system) of leaf extract to scavenge DPPH radical varied significantly among the tested seven species of medicinal plants in experiment-1 and ranged from 32.12 (Catharanthus roseus) to 38.40 (Boerhavia diffusa) $\mathrm{mg} \mathrm{mL}^{-1}$ leaf methanolic extract (Figure 2). Justicia adhatoda, Andrographis paniculata, Rauvolfia serpentina, Catharanthus roseus and Catharanthus alba shared lowest and statistically identical $\mathrm{IC}_{50}$ values for leaf methanolic extracts to scavenge DPPH. Considering $\mathrm{IC}_{50}$ values of leaf methanolic extract of Justicia adhatoda leaves $\left(35.15 \mathrm{mg} \mathrm{mL}^{-}\right.$ $\left.{ }^{1}\right)$ to scavenge $\mathrm{DPPH}$ as $100 \%$, the relative $\mathrm{IC}_{50}$ in Boerhavia diffusa, Paederia foetida, Catharanthus roseus, Catharanthus alba, Andrographis paniculata and Rauvolfia serpentina were 109.3, 107.1, 91.4, 92.4, 94.1 and $94.1 \%$, respectively.

\subsection{Pigments content}

\subsubsection{Leaf pigments in seven different medicinal plants}

Chlorophyll a content in leaves varied significantly among the tested seven different species of medicinal plants and ranged from 1.151 to $2.347 \mathrm{mg} \mathrm{g}^{-1} \mathrm{FW}$ (Figure 3). Justicia adhatoda leaf showed the highest amount of 
chlorophyll-aa content $\left(2.347 \mathrm{mg} \mathrm{g}^{-1} \mathrm{FW}\right)$ followed by the second highest in Andrographis paniculata leaf $\left(1.639 \mathrm{mg} \mathrm{g}^{-1} \mathrm{FW}\right)$. The lowest value of chlorophyll a content was recorded in Rauvolfia serpentina leaf (1.151 $\mathrm{mg} \mathrm{g}^{-1} \mathrm{FW}$ ). Chlorophyll a content in Boerhavia diffusa, Paederia foetida, Catharanthus roseus, Catharanthus alba, Andrographis paniculata and Rauvolfia serpentina were 54.7, 58.7, 56.6, 56.2, 69.8 and $48.9 \%$ of that in Justicia adhatoda leaf.

Chlorophyll $\mathrm{b}$ content in leaves varied widely among the tested seven species and ranged from 0.498 to 0.900 $\mathrm{mg} \mathrm{g}^{-1}$ FW (Figure 4). Justicia adhatoda leaf showed the highest amount of chlorophyll b content $\left(0.900 \mathrm{mg} \mathrm{g}^{-1}\right.$ FW) followed by the second highest in Andrographis paniculata leaf $(0.795 \mathrm{mg})$ and Paederia foetida leaf $\left(0.780 \mathrm{mg} \mathrm{g}^{-1} \mathrm{FW}\right)$. The lowest content of chlorophyll $\mathrm{b}$ was found in Rauvolfia serpentina leaf $\left(0.498 \mathrm{mg} \mathrm{g}^{-1}\right.$ FW). Other species showed the chlorophyll b content as: Boerhavia diffusa (0.543 $\left.\mathrm{mg} \mathrm{g}^{-1} \mathrm{FW}\right)$, Catharanthus roseus $\left(0.541 \mathrm{mg} \mathrm{g}^{-1} \mathrm{FW}\right)$ and Catharanthus alba $\left(0.521 \mathrm{mg} \mathrm{g}^{-1} \mathrm{FW}\right)$. Considering the chlorophyll $\mathrm{b}$ content in Justicia adhatoda leaf as 100\%, chlorophyll b content in Boerhavia diffusa, Paederia foetida, Catharanthus roseus, Catharanthus alba, Andrographis paniculata and Rauvolfia serpentina were 60.4, 88.3, 60.2, 57.9, 86.7 and $55.4 \%$, respectively.

Chlorophyll $(\mathrm{a}+\mathrm{b})$ content in leaves of seven different medicinal plants varied widely among the tested seven species and ranged from 1.619 to $3.283 \mathrm{mg} \mathrm{g}^{-1} \mathrm{FW}$ (Figure 5). Justicia adhatoda leaf showed the highest amount of chlorophyll $(\mathrm{a}+\mathrm{b})$ content as $3.283 \mathrm{mg} \mathrm{g}^{-1} \mathrm{FW}$ followed by the second highest in Andrographis paniculata leaf $\left(2.420 \mathrm{mg} \mathrm{g}^{-1} \mathrm{FW}\right)$. The lowest value of chlorophyll $(\mathrm{a}+\mathrm{b})$ content found in Rauvolfia serpentina leaf $\left(1.619 \mathrm{mg} \mathrm{g}^{-1} \mathrm{FW}\right)$. The other leaves showed the chlorophyll $(\mathrm{a}+\mathrm{b})$ content as Boerhavia diffusa $(1.831 \mathrm{mg}$ $\left.\mathrm{g}^{-1} \mathrm{FW}\right)$, Paederia foetida (2.174 $\left.\mathrm{mg} \mathrm{g}^{-1} \mathrm{FW}\right)$, Catharanthus roseus $\left(1.871 \mathrm{mg} \mathrm{g}^{-1} \mathrm{FW}\right)$ and Catharanthus alba (1.841 $\left.\mathrm{mg} \mathrm{g}^{-1} \mathrm{FW}\right)$. Considering the value of chlorophyll (a+b) content in Justicia adhatoda leaf as 100\%, chlorophyll (a+b) content in Boerhavia diffusa, Paederia foetida, Catharanthus roseus, Catharanthus alba, Andrographis paniculata and Rauvolfia serpentina were found as 55.8, 66.3, 57.0, 56.2, 73.8 and 49.4\%, respectively.

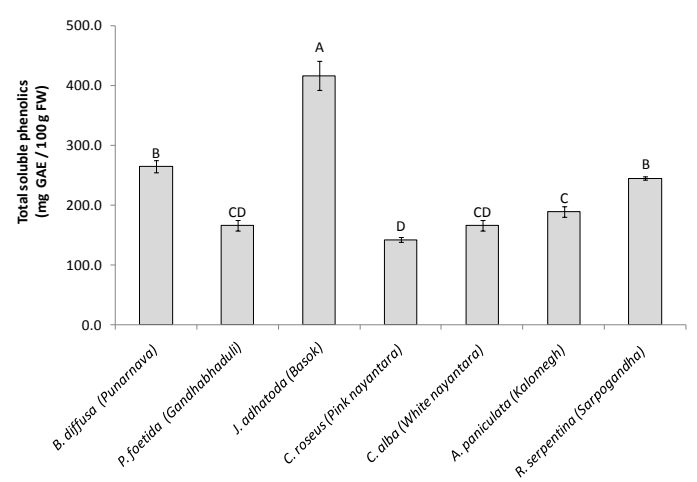

Figure 1. Total soluble phenolics content in the leaves of seven different medicinal plants. It is expressed as $\mathrm{mg}$ gallic acid equivalent (GAE)/100 $\mathrm{g}$ of leaf fresh weight (FW). Each data point is the average of three replicates \pm SEM. Bars sharing common letter are statistically identical but those having different letters are significantly different from each other at $\mathrm{P} \leq 0.05$.

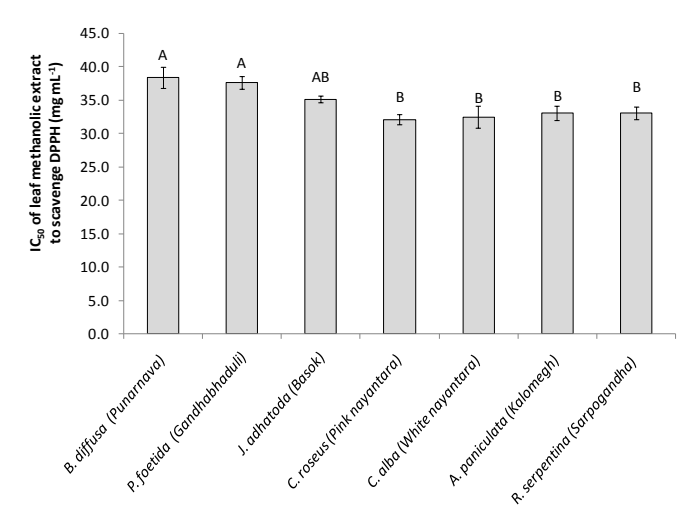

Figure 2. $\mathrm{IC}_{50}$ values for methanolic extracts of leaves from seven different medicinal plants to scavenge DPPH radical. Each data point is the average of three replicates \pm SEM. Bars sharing common letter are statistically identical but those having different letters are significantly different from each other at $P \leq$ 0.05. 


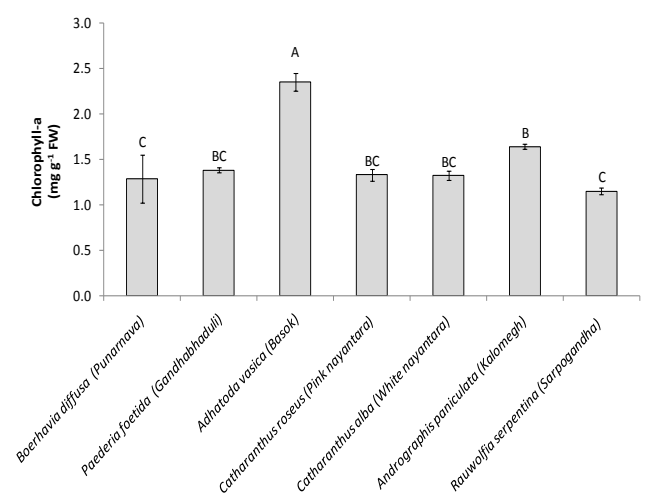

Figure 3. Chlorophyll-a content in leaves of seven different medicinal plants. Each data point is the average of three replicates \pm SEM. Bars sharing common letter are statistically identical but those having different letters are significantly different from each other at $\mathbf{P} \leq \mathbf{0 . 0 5}$.

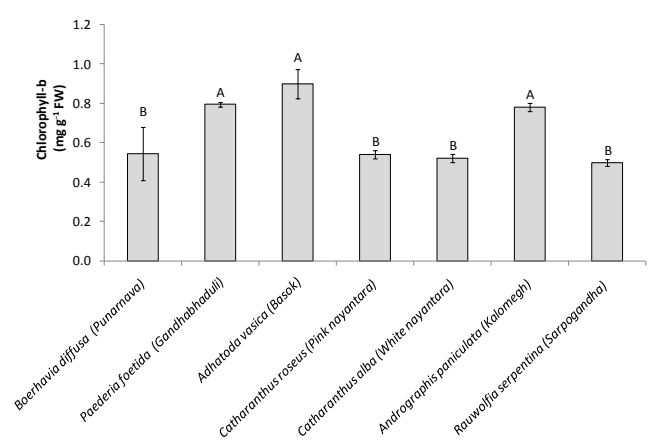

Figure 4. Chlorophyll-b content in leaves of seven different medicinal plants. Each data point is the average of three replicates \pm SEM. Bars sharing common letter are statistically identical but those having different letters are significantly different from each other at $\mathbf{P} \leq \mathbf{0 . 0 5}$.

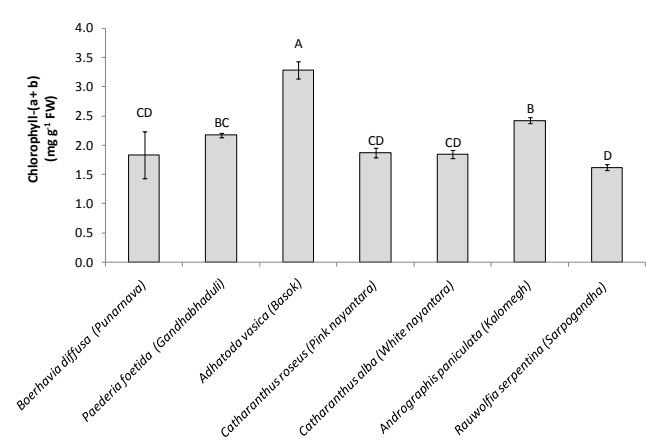

Figure 5. Chlorophyll-(a+b) content in leaves of seven different medicinal plants. Each data point is the average of three replicates \pm SEM. Bars sharing common letter are statistically identical but those having different letters are significantly different from each other at $\mathbf{P} \leq \mathbf{0 . 0 5}$.

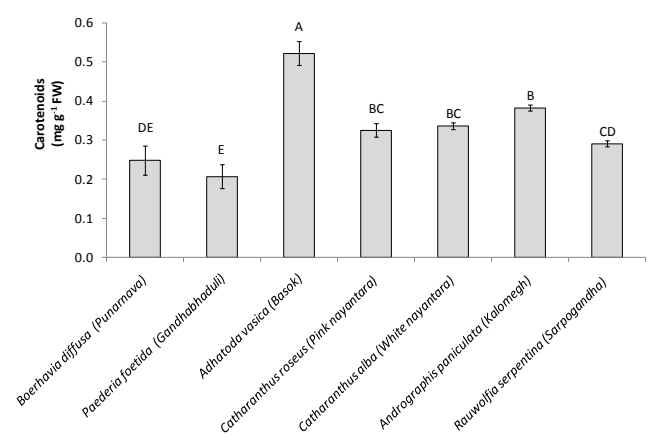

Figure 6. Amount of carotenoids in leaves of seven different medicinal plants. Each data point is the average of three replicates \pm SEM. Bars sharing common letter are statistically identical but those having different letters are significantly different from each other at $\mathbf{P} \leq \mathbf{0 . 0 5}$. 
Total carotenoids content in leaves varied widely among the tested seven species and ranged from 0.206 to $0.521 \mathrm{mg} \mathrm{g}^{-1} \mathrm{FW}$ (Figure 6). Justicia adhatoda leaf showed the highest amount of carotenoids content as 0.521 $\mathrm{mg} \mathrm{g}^{-1}$ FWfollowed by the second highest in Andrographis paniculata leaf $\left(0.382 \mathrm{mg} \mathrm{g}^{-1} \mathrm{FW}\right)$. The lowest value of carotenoids content found in Paederia foetida leaf $\left(0.206 \mathrm{mg} \mathrm{g}^{-1} \mathrm{FW}\right)$. The other species showed the carotenoids content as: Boerhavia diffusa $\left(0.258 \mathrm{mg} \mathrm{g}^{-1} \mathrm{FW}\right)$, Rauvolfia serpentina $\left(0.290 \mathrm{mg} \mathrm{g}^{-1} \mathrm{FW}\right)$, Catharanthus roseus $\left(0.325 \mathrm{mg} \mathrm{g}^{-1} \mathrm{FW}\right)$ and Catharanthus alba $\left(0.336 \mathrm{mg} \mathrm{g}^{-1} \mathrm{FW}\right)$. Carotenoids in Boerhavia diffusa, Paederia foetida, Catharanthus roseus, Catharanthus alba, Andrographis paniculata and Rauvolfia serpentina were calculated as $47.7,39.8,62.5,64.6,73.5$ and $55.9 \%$, to that in $A$. vasica, respectively.

\section{Discussion}

Phenolic chemical compounds are the most important groups of secondary metabolites in medicinal herbs and dietary plants that are characterized by having at least one aromatic ring (C6) bearing one or more hydroxyl groups. Various phenolic compounds (e.g., benzoic and cinnamic acid, coumarins, tannins, lignins, lignans, flavonoids and etc.) have a wide range of beneficial biological functions, including antioxidant activity. Unique structure and a high tendency of phenolic compounds for metal chelation and their redox properties allow them to act as reducing agents, hydrogen donators, and singlet oxygen quenchers which could lead to anti-oxidant activity (Khoddami et al., 2013; Bhatt and Negi, 2012).

In this study, total phenolics content in the methanolic extracts of leaf was found in the order as: Adhatoda vasica (basok) >Boerhavia diffusa (punarnava) $>$ Rauvolfia serpentina (sarpogandha) $>$ Andrographis paniculata (kalomegh) $>$ Paederia foetida $>$ Catharanthus alba (white nayantara) $>$ Catharanthus roseus (pink nayantara) (Figure 1). Adhatoda vasica is an ayurvedic medicinal plant which is a home remedy for several diseases related to respiratory disorders such as asthma, acute and chronic cough, and bronchitis (Mamta et al., 2015). In the present study, the highest phenolics content in Adhatoda vasica leaves among the seven important medicinal plants reveals the importance of this plant in favour of being strong position in folk medicine. Presence of high quantity of total polyphenolic compounds in Adhatoda vasica leaf gives significant antidiabetic, hypolipidemic, expectorant and emulsifying agent (Kumari et al., 2013). In our study, second highest content of phenolics was observed in Boerhavia diffusa and Rauwolfia serpentina leaves. Studies have revealed that Boerhavia diffusa is an excellent diuretic, anti-inflammatory, mild laxative and is a heart tonic. Boerhavia diffusa is also used in treating obesity, improving appetite, jaundice and general fever (Bhowmik et al., 2012).

DPPH is a stable free radical and accepts an electron or hydrogen radical to become a stable diamagnetic molecule. The antioxidants in the sample scavenge this free radical. This method is widely used to evaluate the free radical scavenging capacity of natural antioxidants (Maharana et al., 2010). In this study $\mathrm{IC}_{50}\left(\mathrm{IC}_{50}\right.$ is defined as the amount of antioxidant material required to scavenge $50 \%$ of free radical in the assay system) of plant extracts to scavenge DPPH were assayed for the studied medicinal plants. The $\mathrm{IC}_{50}$ values are considered to be inversely proportional to the antioxidant activity of plant extract (Nisha et al., 2009).

Among the seven different medicinal plants studied basok (Adhatoda vasica), pink nayantara (Catharanthus roseus), white nayantara (Catharanthus alba), kalomegh (Andrographis paniculata) and sarpogandha (Rauwolfia serpentina) possessed statistically highest amount of antioxidative activity, while punarnava (Boerhavia diffusa) and gandhabhaduli (Paederia foetida) were ranked as second highest.

Among the seven different medicinal plants studied in the experiment, the highest chlorophyll-a, chlorophyll-b, chlorophyll- $(\mathrm{a}+\mathrm{b})$ and carotenoids content was detected in Adhatoda vasica leaf (Figures 3-5). Chlorophyll is a green pigment consists of tetrapyrrole ring with a central magnesium ion. It has a long hydrophobic phytol chain in its structure. It is found in some varieties in plants and algae (Aminot and Rey, 2000). In tumor or cancer therapy chlorophyll or chlorophyll derivatives can be utilized as a photodynamic agent (Brandis et al., 2006).

\section{Conclusions}

From the above summary of results for seven different medicinal plants Adhatoda vasica and Catharanthus roseus leaf contained the highest and lowest amount of phenolics, respectively. While highest radical scavenging ability was detected in A. vasica, $C$. roseus, $C$. alba, A. paniculata and $R$. serpentina leaves; the lowest was detected in $B$. diffusa and P. foetida. A. vasica leaf showed the highest amount of chlorophyll-a, chlorophyll-b, chlorophyll-(a+b) and carotenoids. In contrast, lowest amount of chlorophyll-a, chlorophyll-b, chlorophyll- $(\mathrm{a}+\mathrm{b})$ and carotenoids were detected in the $P$. foetida leaf.

\section{Conflict of interest}

None to declare. 


\section{References}

Aminot A and F Rey, 2000. Standard procedure for the determination of chlorophyll $a$ by spectroscopic methods. International Council for the Exploration of the Sea ISSN 0903-2606.

Bhatt P and PS Negi, 2012. Antioxidant and antibacterial activities in the leaf extracts of Indian Borage (Plectranthu samboinicus). Food. Nutr. Sci., 3: 146-152

Bhowmik D, K Kumar, A Dutta, A PdYadav, S Paswan, S Srivastava and L Deb, 2012. Recent trends in potential traditional indian herbs Emblica officinalis and its medicinal importance. J. Pharmacogn. Phytochem., 1: 346-368.

Brandis AS, Y Salomon and A Scherz, 2006. Chlorophyll sensitizers in photodynamic therapy. Photosynth. Res., 25: 461-483.

Brand-Williams W, ME Cuvelier and TCLW Berset, 1995. Use of a free radical method to evaluate antioxidant activity. Food Sci. Technol., 28: 25-30.

Khoddami A, MA Wilkes and TH Roberts, 2003. Techniques for analysis of phenolic compounds. Molecules., 18: 2328-2375.

Kumari R, P Rathi, CS Rajput and SS Sawhney, 2013. Therapeutic characteristics of Rauvolfia serpentina. J. Pharmacol. Chem Sci., 2: 348-355.

Lichtenthaler HK, 1987. Chlorophylls and Carotenoids: Pigments of Photosynthetic Biomembranes. Methods in Enzymol., 148: 350-382.

Maharana L, S Pattnaik, DM Kar, PK Sahu and SC Si, 2010. Anti-Hyperglycemic potential of aqueous extract of leaves of Solanum nigrum Linn. Der Pharma Lettre., 3: 333-345.

Mamta P, B Sujata, KS Rakesh and Rachna, 2015. Antioxidant and Free Radical Scavenging Potential of Ethanolic Fraction of Adhatoda vasica in A549 Cell Line. Asian J. Pharm. Clin. Res., 249.

Mishra S, V Aeri, PK Gaur and SM Jachak, 2014. Phytochemical, Therapeutic and Ethnopharmacological overview for a traditionally important Herb: Boerhavia Diffusa Linn. BioMed Res. Int., 6: 2014.

Nadeem S, Z Ahmad and A Malik, 2012. Mini review: Chemical constituents from Boerhavia species. Stu. Jour. Chem., 1: 45-56.

Nisha P, NP Abdul and P Jayamurthy, 2009. A comparative study on antioxidant activities of different varieties of Solanum melongena. Food Chem. Toxicol., 47: 2640-2644.

Rathi B, R Kumari, A Rani and S Bhatnagar, 2013. Rauvolfia serpentina L. Benth. ex Kurz.: phytochemical, pharmacological and therapeutic aspects. Int. J. Pharm. Sci. Rev. Res., 23: 348-355.

Sain M and V Sharma, 2013. Catharanthus roseus (An anti-cancerous drug yielding plant) - A Review of potential therapeutic properties. Int. J. A. Pharma. Biol. Res., 1: 139-142.

Sanjeev K and DK Nayan, 2015. A brief review on medicinal property of vasa (Adhatoda vasica Linn Nees) from kosha and nighantus. Int. Ayur. Med. Journal., 2: 2181-2182.

Shen YC, CF Chen and F Chiou, 2002. Andrographolide prevents oxygen radical production by human neutrophils: possible mechanism (s) involved in its anti-inflammatory effect. Bri. J. Pharmacol., 135: 399406.

Skrovankova S, L Misurcova and L Machu, 2012. Antioxidant activity and protecting health effects of common medicinal plants. Adv. Food Nutri. Res., 67: 75-139.

Yusuf S, BA Adelaiye and AK Agunu, 2009. Effect of Ziziphus mauritiania (L.) Seed Extracts on Spatial Recognition Memory of Rats as Measured by the Y-Maze Test. Jour. Natarul Prod., 10: 31-39. 